\title{
Analysis of In vitro Fertilizing Capacity to Evaluate the Freezing Procedures of Boar Semen and to Predict the Subsequent Fertility
}

\author{
E Sellés, J Gadea, R Romar, C Matás and S Ruiz \\ Department of Physiology, Faculty of Veterinary Medicine, University of Murcia, Spain
}

\section{Contents}

A porcine in vitro fertilization (IVF) system and seminal quality parameters of frozen-thawed boar semen were used to assess the effectiveness of two different thawing rates of frozen boar semen, and to address the question of whether differences between fertility of ejaculates could be predicted in a limited field trial.

In the first experiment, two thawing procedures were analysed $\left(37^{\circ} \mathrm{C}, 30 \mathrm{~s} ; 50^{\circ} \mathrm{C}, 12 \mathrm{~s}\right)$ and no differences in sperm quality were found. However, when the procedure was $50^{\circ} \mathrm{C}$, $12 \mathrm{~s}$ the IVF results showed a higher number of sperm per penetrated oocyte and a near 10 points higher rate of pronuclear formation.

In the second experiment, the fertility results obtained in the limited field trial show to be efficient enough for application in a commercial use, especially for three of the employed boars (fertility $\geq 80 \%$ ). In this limited study, the conventional seminal parameters are not accurate enough to discriminate good and bad boars in relation to fertility. On the contrary, parameters of in vitro penetrability are more precise to predict subsequent fertilities.

As conclusion, the IVF fertilization system seems to be a good tool to evaluate the quality of frozen-thawed boar semen previous to its commercial way, to verify the bank semen storage quality and a good way to assay new sperm freezing procedures, as it is the more precise evaluating method in estimating the potential fertilizing ability.

\section{Introduction}

Despite almost 40 years of research in freezing of boar semen, the fertility results are not satisfactory enough for commercial use as it is in other domestic animals. However boar frozen-thawed semen is still a valuable tool as a complement to artificial insemination (AI) with fresh semen in some conditions. As it can be stored for a long time, it facilitates the supply of genetic material, as well as building up gene banks to encourage breeds or valuable individuals. In the last years, an increasing effort has been made to improve the fertility results mainly by to ways: first the design of better freezing methods in order to obtain acceptable semen quality (freezing procedures, diluents and cryoprotectants, packages, etc.) (reviewed by Bwanga 1991; Johnson et al. 2000), secondly with optimal routines for heat detection and timing of insemination close to the ovulation (Waberski et al. 1994)

Evaluation of the quality of frozen-thawed semen is an important goal and great deals of assays have been developed (Johnson et al. 1996). Besides, assays including the study of gamete interaction might lead to a better way of predicting male fertility than routine laboratory evaluation of semen (Gadea et al. 1998; Larsson and Rodriguez-Martinez 2000). Some of these assays have been shown to be good tools for evaluating the fertilizing capacity of diluted boar semen (Ivanova and Mollova 1993; Gadea et al. 1998; Xu et al., 1998). However, little information is available about frozen boar semen (Hammitt et al. 1989; Gadea et al. 2001; Pelaez et al. 2001), but it would be very useful to evaluate freezing procedures (Eriksson et al. 2000).

One of the most important factors related with the success of freezing procedures seems to be the thawing rate of semen (Johnson et al. 2000). So, the critical temperature range during thawing is an important factor affecting spermatozoan viability (Fiser et al. 1993). However, it has been demonstrated that the effectiveness of thawing rate also depends on the original rate of freezing (Mazur 1985). Different studies have previously described that when thawing rate is increased (in an optimum range), the motility and acrosome integrity are improved (Pursel and Johnson 1975; Fiser et al. 1993).

For these reasons the objectives of this study were to study the application of the in vitro fertilization (IVF) systems: (1) to assess the effectiveness of two different thawing rates of frozen boar semen, and (2) to address the question of whether differences between fertility of ejaculates could be predicted with semen quality parameters and with IVF fertilization systems in a limited field trial.

\section{Material and Methods}

\section{Semen collection and freezing}

Semen was regularly collected from five mature fertile boars (one Belgium Landrace and four Pietrain 18-30 month-old boars) using the hand method and a dummy. Sperm-rich fraction was collected in a prewarmed thermos flask and the gel-fraction was held on a gauze tissue covering the thermos opening. The volume of the sperm-rich fraction of the ejaculate was measured in a graduated cylinder and sperm concentration measured with a haemacytometer (Neubauer, Brand, Wertheim, Germany) within $20 \mathrm{~min}$ after collection and prior to extension of the semen with isothermal Betsville thawing solution (BTS; Minitüb, Tiefenbach, Germany) extender at a ratio of $1: 1$. Semen was stored at $22^{\circ} \mathrm{C}$ for $2 \mathrm{~h}$, and processed according to the straw-freezing procedure described by Westendorf et al. (1975) and Almlid and Johnson (1988). Briefly, diluted semen was placed at $15^{\circ} \mathrm{C}$ for $150 \mathrm{~min}$ (in a water bath placed into a freezer) and later centrifuged at $800 \times \boldsymbol{g}$ for $10 \mathrm{~min}$. The supernatant was discarded and the semen pellet was re-suspended with lactose-egg yolk extender (LEY; $80 \mathrm{ml}$ of $11 \%$ lactose and $20 \mathrm{ml}$ egg yolk) to provide 
$1.5 \times 10^{9}$ spermatozoa per $\mathrm{ml}$. Then, it was cooled at $5^{\circ} \mathrm{C}$ for $90 \mathrm{~min}$ (in a water bath placed into a freezer) and two parts of LEY extender semen were mixed with LEY extender with $9 \%$ glycerol and $1.5 \%$ Orvus Es Paste (Equex-Paste; Minitüb, Tiefenbach, Germany). The final concentration of semen to be frozen was $1 \times 10^{9}$ spermatozoa per $\mathrm{ml}$ and $3 \%$ glycerol. The cooled semen was leaded into $0.5 \mathrm{ml}$. straws (Minitüb, Tiefenbach, Germany) and sealed with polyvinyl alcohol. Straws were wiped dry and the air bubble was brought to the centre of the straw. The straws were placed in contact with nitrogen vapour about $3 \mathrm{~cm}$ above the liquid nitrogen level for $20 \mathrm{~min}$ in an expandable polystyrene box, plunged into the nitrogen tank and stored until use (1-3 months later). Straws were thawed in a circulating water bath at $50^{\circ} \mathrm{C}$ for $12 \mathrm{~s}$ or at $37^{\circ} \mathrm{C}$ for $30 \mathrm{~s}$ and immediately diluted in $10 \mathrm{ml}$ BTS at $37^{\circ} \mathrm{C}$.

\section{Seminal parameters}

Sperm motility and movement quality were determined placing two sub-samples on warm glass slides $\left(39^{\circ} \mathrm{C}\right)$ and examined under a light microscope $(100 \times$ magnification). The percentage of motile sperm cells was subjectively estimated to the nearest $5 \%$ and the forward progressive motility (FPM) using an arbitrary scale of $0-5$.

The proportion of spermatozoa with a normal apical ridge (NAR) was evaluated after fixed in buffered $2 \%$ glutaraldehyde solution and examined under a phasecontrast microscope (Leica DMR, Wetzlar, Germany) $(1000 \times$ magnification) to analyse acrosomes (Pursel et al. 1972). The NAR was determined on two slides per sample and a total of 300 spermatozoa per sample.

Eosin-nigrosin (EN) viability staining of sperm was also studied. It was diluted at a ratio of $1: 1$ a semen sample with staining solution $(5 \%$ yellow eosin, $10 \%$ nigrosin in a citrate solution $\mathrm{pH}=7.4$ ) and smeared. After air-fixed stained spermatozoa were observed and evaluated 200 sperm per sample (Bamba 1988).

Sperm membrane integrity was evaluated applying a combination of the fluorophores carboxyfluorescein diacetate (DCF) and propidium iodide (Harrison and Vickers 1990) on at least 200 cells per sample using an epifluorescence microscope.

\section{In vitro maturation and in vitro fertilization}

Ovaries from pre-puberal gilts were obtained at a local slaughterhouse, and transported to the laboratory in saline $(0.9 \% \mathrm{w} / \mathrm{v} \mathrm{NaCl})$ with $100 \mathrm{mg} / \mathrm{l}$ kanamycin at $35^{\circ} \mathrm{C}$. Oocytes surrounded by cumulus cells, were slicing from 3 to $6 \mathrm{~mm}$ diameter follicles and washed twice in $35 \mathrm{~mm}$ plastic Petri dishes containing Dulbecco's phosphate-buffered saline modified supplemented with $1 \mathrm{mg} / \mathrm{ml}$ polyvinyl alcohol and $0.005 \mathrm{mg} / \mathrm{ml}$ red phenol. They were washed twice again in maturation medium previously equilibrated for a minimum of $3 \mathrm{~h}$ at $38.5^{\circ} \mathrm{C}$ under $5 \% \mathrm{CO}_{2}$ in maximally humidified air.

The medium used for oocyte maturation was Waymouth-supplemented as previously described (Coy et al. 1999) with $10 \mathrm{UI} / \mathrm{ml}$ pregnant mare serum gonadotro- phin (PMSG), $10 \mathrm{UI} / \mathrm{ml}$ human chorionic gonadotropin (hCG), $1 \mu \mathrm{g} / \mathrm{ml}$ oestradiol-17b, 10\% (v/v) foetal calf serum and $10 \%$ porcine follicular fluid $(\mathrm{v} / \mathrm{v})$. The maturation medium was disposed in three droplets of $100 \mu$ covered with paraffin oil per dish, 20 oocytes per droplet and kept at $38^{\circ} \mathrm{C}$ under $5 \% \mathrm{CO}_{2}$ in air. After 20 $22 \mathrm{~h}$ of culture in maturation medium the oocytes were transferred to fresh maturation medium without hormonal supplements, washed twice and cultured for an additional 20-22 h (Funahashi and Day 1993).

The in vitro fertilization medium was TCM199supplemented as previously described (Coy et al. 1999) with $12 \%$ heat-inactivated foetal calf serum, $0.9 \mathrm{mM}$ sodium pyruvate, $3.05 \mathrm{mM}$ D-glucose, $8.75 \mathrm{mM}$ calcium lactate, $0.68 \mathrm{mM}$ penicillin $\mathrm{G}, 3.6 \mathrm{mM}$ caffeine and $0.068 \mathrm{mM}$ streptomycin sulphate at $\mathrm{pH}=7.4$.

After thawing, the sperm samples were centrifuged at $50 \times \mathbf{g}$ for $3 \mathrm{~min}$ and the supernatants at $1200 \times \boldsymbol{g}$ for $3 \mathrm{~min}$. Resulting pellets of spermatozoa were diluted in TCM199-supplemented medium but without calcium lactate nor caffeine. A semen volume of $100 \mu \mathrm{l}$ was introduced into Petri dishes containing $2 \mathrm{ml}$ of fertilization medium (final concentration of $1 \times 10^{6}$ spermatoza $/ \mathrm{ml}$ ) and 20 in vitro matured oocytes previously washed twice in equilibrated fertilization medium. After $18 \mathrm{~h}$ the cultured oocytes were fixed in 3:1 ethanol : acetic acid for $24 \mathrm{~h}$, stained with $1 \%$ lacmoid and examined under a phasecontrast microscope to asses penetration (PEN) rate, mean number of sperm per penetrated oocyte $(\mathrm{S} / \mathrm{O})$, monospermy (MON) rate and rate of male pronuclear formation (MPF).

\section{Fertility trial}

The fertility study was conducted on a commercial farm, using a total of 45 multiparous (two to seven pregnancies) crossbred sows. Oestrus was checked daily in the presence of a mature teaser boar. Occurrence of oestrus was defined by the standing reflex in front of a boar (back pressure test) and reddening and swelling of the vulva. The sows were inseminated immediately after thawing the semen at $50^{\circ} \mathrm{C}$ for $12 \mathrm{~s}$ and diluted with BTS to prepare insemination doses containing at least $5 \times 10^{9}$ spermatozoa in $80 \mathrm{ml}$. Insemination took place on $12 \mathrm{~h}$ after the diagnosis of oestrus and was repeated 12 h later, using disposable AI catheters.

Pregnancy diagnosis was performed 23-25 days after AI by ultrasonography. Fertility was measured for every ejaculate as the percentage of sows farrowing to AI. For each sow that farrowed, the number of dead and live piglets was counted and the sum was defined as the total number of piglets born.

\section{Experimental design}

\section{Experiment 1. Thawing process}

Five ejaculates from the same boar were frozen according to the methods described before and were thawed at each of the following test velocities resulting from immersion in water to $37^{\circ} \mathrm{C}$ for $30 \mathrm{~s}$ or at $50^{\circ} \mathrm{C}$ for $12 \mathrm{~s}$. Seminal parameters and IVF capacity were assayed. 


\section{Experiment 2. Fertility trial}

To evaluate the capacity for fertility prediction of different assays and to verify the quality of the frozenthawed semen, ejaculates from five fertile boars were frozen-thawed and they were used both in an IVF system and in a field assay by AI with at least $5 \times 10^{9}$ sperm per dose. Seminal parameters were evaluated and differences between boars were investigated in blind fashion.

\section{Statistical analysis}

Data are presented as mean \pm SEM. Data for all rates were modelled according to the binomial model of parameters and were analysed by two-way ANOVA; considering the thawing procedure and sperm batch as main effects in experience 1 and one-way ANOvA in experience 2 . When ANOVA revealed a significant effect, values were compared by the Tukey test. Differences were considered statistically different at $\mathrm{p}<0.05$.

Linear regression was used to further investigate relationships between litter size and measured semen parameters (Pearson correlation and multiple regression), and logistic regression was used to relate the dichotomous farrowing rate data to the sperm parameters, as previously described by Holt et al. (1997).

\section{Results}

\section{Experiment 1}

The studied thawing velocities had no effect on the sperm quality (Table 1), but a significant difference on the motility and NAR $(\mathrm{p}<0.001)$ was detected between batches. For both treatments the motility and membrane integrity (measured with EN or carboxifluorescein staining) were over $60 \%$.

In relation to the in vitro fertilizing capacity of the sperm, thawed under two different procedures, the results obtained showed a higher number of $\mathrm{S} / \mathrm{O}$ (3.91 vs $3.06, \mathrm{p}<0.001)$ (Table 2) and a near 10 points higher rate of MPF (75.47 vs 65.73, p=0.020) when the procedure was $50^{\circ} \mathrm{C}$ for $12 \mathrm{~s}$. Besides, the sperm batch had a significant effect on the $\mathrm{PEN}$, number of $\mathrm{S} / \mathrm{O}$ and MON rate $(\mathrm{p}<0.001)$.

\section{Experiment 2}

The result of sperm assays showed a significant lower number of intact membrane (EN and DCF) and acrosomal integrity (NAR) for the frozen-thawed sperm from boar PI4 ( $<<0.001$, Table 3). However, all the four IVF parameters were significantly affected by the boar studied and showed a significant lower values for penetrability (PEN and S/O) in PI4 and PI779 boars against the other three (Table 4). In the same way, the MON was affected by boar and showed the highest values for the boars with less penetrability. The MPF was higher than $82 \%$ in all the boars studied and this parameter was not related with fertility (Tables 4 and 5).

The in vitro penetrability results are consistent with the limited data from the fertility field trial, as fertility was significantly affected by boar $(\mathrm{p}=0.019)$, being those with lower penetrability (boars PI4 and PI779) these are with lower fertility $(33 \%)$ than the other three

Table 1. Seminal parameters measured in boar semen thawed under two different procedures (mean \pm SEM)

\begin{tabular}{|c|c|c|c|c|c|}
\hline & Motility (\%) & FPM $(0-5)$ & $\mathrm{EN}(\%)$ & NAR (\%) & DCF $(\%)$ \\
\hline \multicolumn{6}{|l|}{ Thawing velocity } \\
\hline $50^{\circ} \mathrm{C}$ for $12 \mathrm{~s}$ & $62.27 \pm 3.53$ & $3.64 \pm 0.15$ & $76.55 \pm 1.74$ & $49.36 \pm 4.34$ & $66.64 \pm 2.53$ \\
\hline $37^{\circ} \mathrm{C}$ for $30 \mathrm{~s}$ & $60.45 \pm 4.01$ & $3.73 \pm 0.14$ & $72.36 \pm 1.86$ & $48.91 \pm 3.57$ & $63.45 \pm 2.41$ \\
\hline \multicolumn{6}{|l|}{ Source of variability } \\
\hline Thawing velocity & 0.462 & 0.671 & 0.058 & 0.961 & 0.117 \\
\hline Sperm batch & $<0.001$ & 0.125 & 0.221 & $<0.001$ & 0.082 \\
\hline Interaction & 0.459 & 0.658 & 0.132 & 0.850 & 0.053 \\
\hline
\end{tabular}

FPM: forward progressive motility (0-5), EN: eosin-nigrosine stain, NAR: normal apical ridge, DCF: sperm membrane integrity assessed with carboxyfluorescein diacetate.

Table 2. The IVF results (mean \pm SEM) for mature oocytes fertilized with frozen-thawed boar semen under two different procedures: rate of penetration $(\% \mathrm{PEN})$, mean number of spermatozoa per penetrated oocyte $(\mathrm{S} / \mathrm{O})$, monospermy rate $(\%$ MON) and rate of male pronuclear formation ( $\% \mathrm{MPF})$

\begin{tabular}{|c|c|c|c|c|c|}
\hline & $\mathrm{n}$ & $\%$ PEN & $\mathrm{S} / \mathrm{O}^{*}$ & $\% \mathrm{MON}^{*}$ & $\% \mathrm{MPF}^{*}$ \\
\hline \multicolumn{6}{|l|}{ Thawing velocity } \\
\hline $50^{\circ} \mathrm{C}$ for $12 \mathrm{~s}$ & 230 & $69.13 \pm 3.05$ & $3.91 \pm 0.27^{\mathrm{a}}$ & $33.96 \pm 3.77$ & $75.47 \pm 3.42^{\mathrm{a}}$ \\
\hline $37^{\circ} \mathrm{C}$ for $30 \mathrm{~s}$ & 254 & $70.08 \pm 2.88$ & $3.06 \pm 0.19^{\mathrm{b}}$ & $34.83 \pm 3.58$ & $65.73 \pm 3.57^{\mathrm{b}}$ \\
\hline \multicolumn{6}{|l|}{ Source of variability } \\
\hline Thawing velocity & 0.840 & $<0.001$ & 0.641 & 0.020 & \\
\hline Sperm batch & $<0.001$ & $<0.001$ & $<0.001$ & 0.654 & \\
\hline Interaction & 0.949 & $<0.001$ & 0.519 & 0.019 & \\
\hline
\end{tabular}

${ }^{*}$ Based on penetrated oocytes.

a,b Numbers within columns with different superscripts differ $(\mathrm{p}<0.05)$

n: number of oocytes. 
Table 3. Seminal parameters measured in sperm thawed from five different boars used in the fertility trial (mean \pm SEM)

\begin{tabular}{|c|c|c|c|c|c|}
\hline & Motility (\%) & FPM $(0-5)$ & $\mathrm{EN}(\%)$ & NAR $(\%)$ & DCF $(\%)$ \\
\hline \multicolumn{6}{|l|}{ Boar } \\
\hline BB & $62.00 \pm 2.00$ & $3.95 \pm 0.05$ & $72.50 \pm 2.88^{\mathrm{a}}$ & $42.50 \pm 3.49^{\mathrm{a}}$ & $69.75 \pm 3.17^{\mathrm{a}}$ \\
\hline PI4 & $59.37 \pm 2.17$ & $3.75 \pm 0.06$ & $53.69 \pm 2.51^{\mathrm{b}}$ & $33.34 \pm 2.48^{b}$ & $41.71 \pm 3.78^{b}$ \\
\hline PI67 & $63.70 \pm 1.55$ & $3.88 \pm 0.04$ & $66.31 \pm 1.40^{\mathrm{a}}$ & $39.97 \pm 1.44^{\mathrm{a}}$ & $53.69 \pm 3.48^{\mathrm{ab}}$ \\
\hline PI779 & $58.92 \pm 0.82$ & $3.85 \pm 0.04$ & $70.73 \pm 1.61^{\mathrm{a}}$ & $46.76 \pm 1.38^{\mathrm{a}}$ & $57.41 \pm 2.52^{\mathrm{a}}$ \\
\hline PI89 & $59.30 \pm 0.80$ & $3.86 \pm 0.03$ & $69.20 \pm 1.18^{\mathrm{a}}$ & $51.16 \pm 1.30^{\mathrm{a}}$ & $56.47 \pm 2.41^{\mathrm{a}}$ \\
\hline \multicolumn{6}{|c|}{ Source of variability } \\
\hline Boar & 0.053 & 0.208 & $<0.001$ & $<0.001$ & $<0.001$ \\
\hline
\end{tabular}

FPM: forward progressive motility (0-5), EN: eosin-nigrosine stain, NAR: normal apical ridge, DCF: Sperm membrane integrity assessed with carboxyfluorescein diacetate.

${ }^{\mathrm{a}, \mathrm{b}}$ Numbers within columns with different superscripts differ $(\mathrm{p}<0.05)$.

Table 4. The IVF and in vivo fertility results (mean \pm SEM) for mature oocytes fertilized with frozen-thawed semen from five different boars: rate of penetration $(\mathrm{PEN})$, mean number of spermatozoa per penetrated oocyte $(\mathrm{S} / \mathrm{O})$, monospermy rate $(\% \mathrm{MON})$ and rate of male pronuclear formation (MPF)

\begin{tabular}{|c|c|c|c|c|c|c|c|}
\hline & $\mathrm{n}$ & PEN (\%) & $\mathrm{S} / \mathrm{O}^{*}$ & $\operatorname{MON}^{*}(\%)$ & $\operatorname{MPF}^{*}(\%)$ & Fertility $(\%)$ & Litter size \\
\hline \multicolumn{8}{|l|}{ Boar } \\
\hline BB & 199 & $62.81 \pm 3.43^{\mathrm{cd}}$ & $2.78 \pm 0.28^{\mathrm{a}}$ & $48.80 \pm 4.49^{\mathrm{ab}}$ & $88.80 \pm 2.83^{\mathrm{ab}}$ & $80(4 / 5)$ & $11.5 \pm 1.19$ \\
\hline PI4 & 212 & $44.34 \pm 3.42^{\mathrm{b}}$ & $1.65 \pm 0.13^{\mathrm{b}}$ & $61.70 \pm 5.04^{\mathrm{ab}}$ & $82.98 \pm 3.90^{\mathrm{b}}$ & $33.33(2 / 6)$ & $6 \pm 0$ \\
\hline PI67 & 329 & $67.17 \pm 2.59^{\mathrm{d}}$ & $2.21 \pm 0.11^{\mathrm{ab}}$ & $40.72 \pm 3.31^{\mathrm{b}}$ & $87.33 \pm 2.24^{\mathrm{b}}$ & $84.62(11 / 13)$ & $9.18 \pm 1.54$ \\
\hline PI779 & 320 & $23.13 \pm 2.36^{\mathrm{a}}$ & $1.63 \pm 0.13^{\mathrm{b}}$ & $63.51 \pm 5.63^{\mathrm{a}}$ & $94.59 \pm 2.65^{\mathrm{ab}}$ & $33.33(3 / 9)$ & $10.67 \pm 0.67$ \\
\hline PI89 & 308 & $52.27 \pm 2.85^{\mathrm{bc}}$ & $2.54 \pm 0.18^{\mathrm{a}}$ & $50.93 \pm 3.95^{\mathrm{b}}$ & $98.14 \pm 1.07^{\mathrm{a}}$ & $83.33(10 / 12)$ & $7.3 \pm 1.46$ \\
\hline \multicolumn{8}{|c|}{ Source of variability } \\
\hline Boar & $<0.001$ & $<0.001$ & 0.001 & $<0.001$ & 0.019 & 0.405 & \\
\hline
\end{tabular}

*Based on penetrated oocytes.

a,b,c,d Numbers within columns with different superscripts differ $(\mathrm{p}<0.05)$.

n: number of oocytes.

Table 5. Logistic regression of seminal parameters with fertility result (farrowing rate)

\begin{tabular}{lcccc}
\hline Variable & Coefficient $B$ & SE & $t$ & Significance (p) \\
\hline PEN & 0.0208 & 0.0071 & 2.9402 & 0.0033 \\
S/O & 0.4384 & 0.1758 & 2.4935 & 0.0127 \\
MPF & 0.0063 & 0.0035 & 1.8046 & 0.0711 \\
MON & 0.0043 & 0.0050 & 0.8577 & 0.3910 \\
Motility & 0.0115 & 0.0051 & 2.2360 & 0.0253 \\
FPM & 0.1842 & 0.0821 & 2.2445 & 0.0248 \\
EN & 0.0107 & 0.0047 & 2.2654 & 0.0235 \\
NAR & 0.0164 & 0.0072 & 2.2870 & 0.0222 \\
DCF & 0.0135 & 0.0058 & 2.3482 & 0.0189 \\
\hline
\end{tabular}

PEN: rate of penetration, $\mathrm{S} / \mathrm{O}$ : mean number of spermatozoa per penetrated oocyte, MPF: rate of male pronuclear formation, MON: monospermy rate, FPM: forward progressive motility (0-5), EN: eosin-nigrosine stain, NAR: normal apical ridge, DCF: Sperm membrane integrity assessed with carboxyfluorescein diacetate, SE: standard error.

with fertility rates over $80 \%$ (Table 4 ). No differences between boars were detected for litter size.

When the logistic regression was analysed between in vitro penetration and seminal parameters with fertility results, significant regression coefficients were found for PEN rate and $\mathrm{S} / \mathrm{O}$, and all the quality seminal parameters (motility, FPM, EN, NAR, DCF; Table 5, $\mathrm{p}<0.05)$. Later, when studying all semen parameters through stepwise on multiple logistic regression forward, only three parameters (PEN, MPF and motility) were included (Table $6, R^{2}=0.492 ; \mathrm{p}<0.001$ ).
Table 6. Multiple logistic regression of seminal measurements with fertility result (farrowing rate)

\begin{tabular}{lrrrc}
\hline Variable & Coefficient & \multicolumn{1}{c}{ SE } & \multicolumn{1}{c}{$t$} & Significance (p) \\
\hline Constant & -46.1846 & 24.9668 & -1.8498 & 0.0643 \\
PEN & 0.3747 & 0.2228 & 1.6813 & 0.0927 \\
MPF & 0.8055 & 0.4882 & 1.6499 & 0.0990 \\
Motility & -0.6857 & 0.5216 & -1.3145 & 0.1887 \\
\hline
\end{tabular}

McFadden's $R^{2}=0.492$; log likelihood: -27.373 ; SE: standard error.

Significance of statistical model $\mathrm{p}<0.001$.

In relation with litter size, significant Pearson correlation was found for all the IVF parameters (except MPF) and two quality parameters (FPM and DCF, Table 7). When a stepwise multivariate analysis was made a significant model $(\mathrm{p}<0.0001)$ constructed only with fertilization parameters of penetrability (PEN and $\mathrm{S} / \mathrm{O}$ ) that may explain the nearly $80 \%$ of variability (Table 8).

\section{Discussion}

To improve the viability and fertilizing capacity of the boar frozen-thawed semen is necessary to optimize all the factors that have an effect in the freezing procedure. In this way we have focused our attention on one of them, the thawing process, and in the assessment methods for frozen semen evaluation. 
Table 7. Linear regression of seminal measurements with average litter size $^{\mathrm{a}}$

\begin{tabular}{lcc}
\hline Variable & Pearson correlation coefficient & Significance $(\mathrm{p})$ \\
\hline PEN & 0.4461 & 0.0031 \\
S/O & 0.4356 & 0.0039 \\
MPF & -0.1421 & 0.3692 \\
MON & -0.4014 & 0.0084 \\
Motility & 0.2789 & 0.0635 \\
FPM & 0.3317 & 0.0260 \\
EN & 0.1968 & 0.1951 \\
NAR & 0.1181 & 0.4399 \\
DCF & 0.3450 & 0.0203 \\
\hline
\end{tabular}

${ }^{a}$ Litter sizes included failed conceptions as zero values.

PEN: rate of penetration, $\mathrm{S} / \mathrm{O}$ : mean number of spermatozoa per penetrated oocyte, MPF: rate of male pronuclear formation, MON: monospermy rate, FPM: forward progressive motility $(0-5), \mathrm{EN}$ : eosin-nigrosine stain, NAR: normal apical ridge, DCF: Sperm membrane integrity assessed with carboxyfluorescein diacetate.

Table 8. Multiple linear regression of seminal measurements with litter size ${ }^{\mathrm{a}}$

\begin{tabular}{lcccc}
\hline Variable & Coefficient & SE & $t$ & $p$ \\
\hline PEN & 0.0609 & 0.0356 & 1.7089 & 0.0952 \\
S/O & 1.4749 & 0.9276 & 1.5900 & 0.1197
\end{tabular}

${ }^{a}$ Litter sizes included failed conceptions as zero values.

$R^{2}=79.54 \% ; \mathrm{p}<0.0001$

PEN: rate of penetration, $\mathrm{S} / \mathrm{O}$ : mean number of spermatozoa per penetrated oocyte.

In the first experiment, we have found no differences in sperm quality with two thawing procedures near to the optimal conditions and previously accepted to thaw frozen boar semen in ministraws (Maxwell and Johnson, 1997; Erkisson et al. 2000). However, Fiser et al. (1993) found that after freezing at optimal rate, the percentage of motile spermatozoa and sperm with NAR increased gradually while increasing warming velocity. They studied a wide range of velocities, some of them out of optimal conditions and those results were related to cryoinjuries made during a slow thawing process by the re-growth of ice crystals (Mazur 1985). Besides this, another problem would be present in the rapid thawing process, as Bamba and Cran (1985) showed that boar spermatozoa might be also severely damaged by warm shock.

Concerning the in vitro PEN capacity only the number of $\mathrm{S} / \mathrm{O}$ and the rate of MPF were significantly affected by the thawing temperature. The capacity of spermatozoa to penetrate oocyte might be assessed by PEN rate as well as S/O (Matttioli et al. 1988). In this study, we have obtained a higher number of $\mathrm{S} / \mathrm{O}$ in the thawing method with the higher temperature. This situation might be caused by a better sperm function not correctly evaluated by classical sperm analysis (Gadea and Matás 2000). Apart from this, it has been reported that a fast velocity is associated to decrease the cellular damage, so that the effect of a fast velocity could minimize the damages associated to structure and DNA stability and a significant decrease on the growth of ice crystals (Mazur 1984). In the same way, the higher rate of MPF obtained with warmer temperature might be in relation with a less intense alteration of sperm chromatin decondensation (White 1993), or the alteration in the number of thiol groups during freezing process (Chatterjee et al. 2001). However, MPF has also been related with others factors such as the content of glutathione in oocyte (Funahashi et al. 1994), the maturation system (Coy et al. 1999) and boar (Xu et al. 1996).

Significant differences associated to batches (motility, NAR, PEN, S/O and MON) would be related to the use of manual methods (nitrogen vapour) difficulty repeatable. This trouble could be solved with the use of programmable freezing procedures and the optimal curve of freezing (Ruiz et al. 2002). Finally, it is obvious that to obtain the best viability after thawing is extremely important to adapt the thawing velocity to the freezing velocity and to the straw volume (Hofmo and Almlid 1990).

The fertility results obtained in the limited field trial (total $66.67 \%, 30 / 45$ ) are efficient enough for application in a commercial use, specially for three of the employed boars $(80,83.33$ and $84.32 \%)$. These results are comparable with those obtained by other authors (Almlid and Hofmo 1996; Bertani et al. 1997; Hofmo and Grevle 1999; Erkisson, 2000). However, the question of whether differences between fertility of ejaculates could be predicted with semen quality parameters and with IVF systems is not yet answered. A wide variability among boars in fertility rates obtained from their frozen semen have been demonstrated in several studies (reviewed by Johnson 1985), and recently a genetic basis of boar semen freezability have been demonstrated (Thurston et al. 2002). However, till now, no method of evaluating the quality of frozen-thawed semen is yet available when attempting to predict fertility.

In this limited study, the conventional seminal parameters are not enough efficient to discriminate good and bad boars in relation to fertility. Only one of the two bad freezer boars with a low fertility was detected by acrosome and membrane integrity assessment. On the contrary, parameters of penetrability (PEN and $\mathrm{S} / \mathrm{O}$ ), measured in an IVF system, are more precise to predict subsequent fertilities. The $\mathrm{S} / \mathrm{O}$ does not reflect the normal fertilization events in vivo, but may provide a useful estimate of spermatozoa with high fertilizing ability.

The results obtained in the IVF system are consistent with in vivo fertility and significant logistic regression was found for PEN and this parameter was included in a multiple model. In this way, in a previous work using diluted fresh semen and a higher number of sows inseminated, a significant relationship was found between in vitro $\mathrm{PEN}$ rate and $\mathrm{S} / \mathrm{O}$ with in vivo fertility and with a similar multiple logistic regression to fertility, where PEN rate and motility were included (Gadea et al. 1998). In this model the motility also appears, but surprisingly the motility change the sign from logistic regression (positive 0.0115 , Table 5) to negative sign in multiple logistic regression $(-0.6857$, Table 6$)$. These non-sense signs must be related with co-linearity among decisive variables as previously we detected in applications of multiple discriminant analysis model for prognosis of in vitro fertility (Gadea and Matás, 2000). The 
logistic regression is a robust method to analyse categorical data such as fertility rate. It is better than lineal regression of transformed data, but the former is difficult to manage with the odds ratio.

On the other hand, a greater difficulty is presented to predict the litter size, probably related with the maternal and environment importance effects (ovulation rate, fertilization rate, relation insemination-ovulation, and so on). So, a fewer number of classical sperm parameters are related and only $\mathrm{PEN}$ and $\mathrm{S} / \mathrm{O}$ are necessary to explain near $80 \%$ of variability.

In the present study the IVF is shown as a precise technique to assess freezing procedures of boar semen. In this way, a limited number of factors related with the freezing process have been evaluated by the use of an IVF system (holding time and type of package (Eriksson et al. 2000) or volume of straw (Cordova et al. 2001, 2002). As conclusion, we can determine that a fast thawing speed had a more positive effect on the fertilizing capacity in vitro of the frozen boar semen. Moreover, the IVF seems to be a good tool to evaluate the quality of frozen-thawed boar semen previous to its commercial way, to verify the bank semen storage quality and a good way to assay new sperm-freezing procedures, as it is the evaluating method more precise in estimating the potential fertilizing ability.

\section{Acknowledgements}

The authors thank Dr A. Romar for statistical review. This work was supported by project FEDER (1FD97-0501) and AGL2000-0485-C0201 .

\section{References}

Almlid T, Hofmo PO, 1996: A brief review of frozen semen application under Norwegian AI service conditions. Reprod Dom Anim 31, 169-173.

Almlid T, Johnson LA, 1988: Effects of glycerol concentration, equilibration time and temperature of glycerol addition on posthaw viability of boar spermatozoa frozen in straws. J Anim Sci 66, 2899-2905.

Bamba K, 1988: Evaluation of acrosomal integrity of boar spermatozoa by bright field microscopy using a eosinnigrosin stain. Theriogenology 29, 1245-1251.

Bamba K, Cran DG, 1985: Effect of rapid warming of boar semen on sperm morphology and physiology. J Reprod Fertil 75, 133-138.

Bertani GR, Scheid IR, Fialho FB, Rubin MIB, Wentz I, Goncalves PBD, 1997: Effect of the time of artificial insemination with frozen-thawed or fresh semen on embryo viability and early pregnancy rate in gilts. Theriogenology 48, 933-945.

Bwanga CO, 1991: Cryopreservation of boar semen. Acta Vet Scand 32, 431-453.

Chatterjee S, de Lamirande E, Gagnon C, 2001: Cryopreservation alters membrane sulfhydryl status of bull spermatozoa: protection by oxidized glutathione. Mol Reprod Dev 60, 498-506.

Cordova A, Perez JF, Lleo B, Garcia Artiga C, Martin Rillo S, 2001: In vitro fertilizing capacity of deep frozen boar semen packaged in 0.5 and $5 \mathrm{ml}$ straws. Reprod Dom Anim 36, 199-202.

Cordova A, Perez JF, Lleo B, Garcia Artiga C, Alvarez A, Drobchak V, Martin Rillo S, 2002: In vitro fertilizing capacity and chromatin condensation of deep frozen boar semen packaged in 0.5 and $5 \mathrm{ml}$ straws. Theriogenology $\mathbf{5 7}$, 2119-2128

Coy P, Ruiz S, Romar R, Campos I, Gadea J, 1999: Maturation, fertilization and complete development of porcine oocytes matured under different systems. Theriogenology 51, 799-812.

Erkisson BM, 2000: Cryopreservation of Boar Semen. Studies on Sperm Viability In vitro and Fertility. Doctoral Thesis, Uppsala.

Eriksson BM, Vazquez JM, Martınez E, Roca J, Lucas X, Rodriguez-Martınez H, 2000: Effects of holding time during cooling and of type of package on plasma membrane integrity, motility and in vitro oocyte penetration ability of frozen-thawed boar spermatozoa. Theriogenology 55, 1593-1605.

Fiser PS, Fairfull RW, Hansen C, Panich PL, Shrestha Underhill L, 1993: The effect of warming velocity on motility and acrosomal integrity of boar sperm as influenced by the rate of freezing and glycerol level. Mol Reprod Dev 34, 190-195.

Funahashi H, Day BN, 1993: Effects of the duration of exposure to hormone supplements on cytoplasmic maturation of pig oocytes in vitro. J Reprod Fertil 98, 179-185.

Funahashi H, Cantley TC, Stumpf TT, Terlow SL, Day BN, 1994: Use of low salt culture medium for in-vitro maturation of porcine oocytes is associated with elevated oocyte glutathione levels and enhanced male pronuclear formation after in vitro fertilization. Biol Reprod 51, 633-639.

Gadea J, Matás C, 2000: Sperm factors related to in vitro penetration of porcine oocytes. Theriogenology 54, 13431357.

Gadea J, Matás C, Lucas X, 1998: Prediction of porcine semen fertility by homologus in vitro penetration (hIVP) assay. Anim Reprod Sci 54, 95-108.

Gadea J, Ruiz S, Sellés E, Romar R, Matás C, Coy P, Poto A, Peinado B, 2001: Use of in vitro fertilization for evaluation of boar semen freezing procedures. ITEA 22, 799-801. (in Spanish).

Hammitt DG, Martin PA, Callanan T, 1989: Correlations between heterospermic fertility and assays of porcine seminal quality before and after cryopreservation. Theriogenology 32, 385-399.

Harrison RAP, Vickers SE, 1990: Use of fluorescent probes to assess membrane integrity in mammalian spermatozoa. J Reprod Fert 88, 343-352.

Hofmo PO, Almlid T, 1990: Recent developments in freezing of boar semen with special enphasis on cryoprotectants. II Boar Semen Preservation, Beltsville, USA 2, 111-122.

Hofmo PO, Grevle IS, 1999: Development and commercial utilization of frozen boar semen in Norway. IV International Conference on Boar Semen Preservation, Beltsville, Maryland, USA, August 8-11, 1999. Abstract of Oral Presentation 09

Holt C, Holt WV, Moore HDM, Reed HCB, Curnock RM, 1997: Objectively measured boar sperm motility parameters correlate with the outcomes of on farm inseminations: results of two fertility trials. J Andrology 18, 312-323.

Ivanova M, Mollova M, 1993: Zona-penetration in vitro test for evaluating boar sperm fertility. Theriogenology 40, 397410.

Johnson LA, 1985. Fertility results using frozen boar spermatozoa. In: Jhonson, LA, Larsson, K (eds), Deep Freezing Boar Semen. Proc 1st Int Conf Deep Freezing of Boar Semen. SLU, Uppsala, pp. 199-223.

Johnson LA, Dobrinsky JR, Welch GR, 1996: Staining sperm for viability assessment. Reprod Dom Anim 31, 37-47. 
Johnson LA, Weitze KF, Fiser P, Maxwell WMC, 2000: Storage of boar semen. Anim Reprod Sci 62, 143-172.

Larsson B, Rodriguez-Martinez H, 2000: Can we use in vitro fertilization tests to predict semen fertility? Anim Reprod Sci 60-61, 327-336.

Matttioli M, Galeati G, Bacci ML, Seren E, 1988: Follicular factors influence oocyte pig oocyte penetrability and cortical granule distribution. Gamete Res 21, 223-232.

Maxwell WMC, Johnson LA, 1997: Membrane status of boar spermatozoa after cooling or cryopreservation. Theriogenology 48, 209-219.

Mazur P, 1984: Freezing of living cells: mechanisms and implications. Anim J Physio 247, 125-142.

Mazur P, 1985: Basic concepts in freezing cells. In: Johnson, LA, Larsson, K (eds), Deep Freezing Boar Semen. Proc 1st Int Conf Deep Freezing of Boar Semen. SLU, Uppsala, pp. 91-111.

Pelaez J, Breininger E, Gonzalez C, Martınez E, Riol JA, Peña FJ, Alegre B, Dominguez JC, 2001: Good quality of postthaw frozen boar semen may not lead to acceptable reproductive performances as evidenced by an homologous in vitro fertilization test. 5th Conference ESDAR, Wienn, 73 pp.

Pursel VG, Johnson LA, 1975: Freezing of boar spermatozoa. Fertilizing capacity with concentrated semen and new thawing procedure. J Anim Sci 40, 99-102.

Pursel VG, Johnson LA, Rampacek GB, 1972: Acrosome morphology of boar spermatozoa incubated before cold shock. J Anim Sci 34, 278-283.

Ruiz S, Selles E, Gadea J, Marco MA, Murgas L, 2002: Effect of freezing rate on boar semen frozen: preliminary results of AI. Theriogenology 57, 480. (abstract).
Thurston LM, Siggins K, Mileham AJ, Watson PF, Holt WV, 2002: Identification of amplified restriction fragment length polymorphism markers linked to genes controlling boar sperm viability following cryopreservation. Biol Reprod 66, 545-554.

Waberski D, Weitze KF, Gleumes T, Schwarz M, Willmen T, Petzoldt R, 1994: Effect of time of insemination relative to ovulation on fertility with liquid and frozen boar semen. Theriogenology 42, 831-840.

Westendorf P, Richter L, Treu H, 1975: Deep freezing of boar sperma. Laboratory and insemination results using the Hülsenberger paillete method. Dtsch Tierarztl Wochenschr 82, 261-267. (in German).

White IG, 1993: Lipids and calcium uptake of sperm in relation to cold shock and preservation: a review. Reprod Fertil Dev 5, 639-658.

Xu X, Ding J, Seth PC, Harbison DS, Foxcroft GR, 1996: In vitro fertilization of in vitro matured pig oocytes: effects of boar and ejaculate fraction. Theriogenology 45, 745-755.

Xu X, Pommier S, Arbov T, Hutchings B, Sotto W, Foxcroft GR, 1998: In vitro maturation and fertilization techniques for assessment of semen quality and boar fertility. J Anim Sci 76, 3079-3089.

Submitted: 05.07.2002

Author's address (for correspondence): J Gadea, Dept. Fisiología, Facultad de Veterinaria, Universidad de Murcia, 30, 100 Murcia, Spain. E-mail: jgadea@um.es 